\title{
Proximal Tubule Cell Hypothesis for Cardiorenal Syndrome in Diabetes
}

\author{
Akihiko Saito, ${ }^{1}$ Ryohei Kaseda, ${ }^{2}$ Michihiro Hosojima, ${ }^{2}$ and Hiroyoshi Sato ${ }^{1}$ \\ ${ }^{1}$ Department of Applied Molecular Medicine, Niigata University Graduate School of Medical and Dental Sciences, \\ 1-757 Asahimachi-dori, Chuo-ku, Niigata 951-8510, Japan \\ ${ }^{2}$ Division of Clinical Nephrology and Rheumatology, Niigata University Graduate School of Medical and Dental Sciences, \\ 1-757 Asahimachi-dori, Chuo-ku, Niigata 951-8510, Japan \\ Correspondence should be addressed to Akihiko Saito, akisaito@med.niigata-u.ac.jp \\ Received 6 September 2010; Accepted 5 November 2010 \\ Academic Editor: Mitchell H. Rosner
}

Copyright (๑) 2011 Akihiko Saito et al. This is an open access article distributed under the Creative Commons Attribution License, which permits unrestricted use, distribution, and reproduction in any medium, provided the original work is properly cited.

Incidence of cardiovascular disease (CVD) is remarkably high among patients with chronic kidney disease (CKD), even in the early microalbuminuric stages with normal glomerular filtration rates. Proximal tubule cells (PTCs) mediate metabolism and urinary excretion of vasculotoxic substances via apical and basolateral receptors and transporters. These cells also retrieve vasculoprotective substances from circulation or synthesize them for release into the circulation. PTCs are also involved in the uptake of sodium and phosphate, which are critical for hemodynamic regulation and maintaining the mineral balance, respectively. Dysregulation of PTC functions in CKD is likely to be associated with the development of CVD and is linked to the progression to end-stage renal disease. In particular, PTC dysfunction occurs early in diabetic nephropathy, a leading cause of CKD. It is therefore important to elucidate the mechanisms of PTC dysfunction to develop therapeutic strategies for treating cardiorenal syndrome in diabetes.

\section{Introduction}

Chronic kidney disease (CKD) is a worldwide public health problem, and the incidence of end-stage renal disease (ESRD) with poor outcomes and associated high costs is increasing. Patients with $\mathrm{CKD}$ are also at high risk of developing cardiovascular disease (CVD). It is therefore important to elucidate the pathogenesis of CKD and the mechanisms underlying its role in the development of CVD.

Albuminuria/proteinuria is a distinctive clinical sign in patients with CKD. Although a decrease in glomerular filtration rate (GFR) correlates with an increase in incidence of CVD, patients showing normal GFR with even mild albuminuria/proteinuria are also at risk of developing CVD $[1,2]$. The link between albuminuria/proteinuria and CVD has generally been attributed to vascular endothelial injury associated with the development of atherosclerosis. However, endothelial injury may not only be a cause of CKD, but also a consequence of the disease. In addition, the vascular pathology of CKD is characterized by medial layer calcification that may be mediated by calcium-phosphate dysregulation [3]. Therefore, to clarify the mechanisms of CVD in patients with CKD, it is important to investigate the renal factors that cause albuminuria/proteinuria and those that are involved in the induction of vascular endothelial injury and calcification.

The aim of this paper is to hypothesize and verify on the basis of the available evidence that proximal tubule cell (PTC) dysfunction explains well the link between the development of albuminuria/proteinuria and cardiovascular risk, especially in diabetic nephropathy which is a leading cause of CKD and is highly associated with the development of CVD.

\section{Overall Functions of PTCs}

The various functions of PTCs include (1) reabsorption and intracellular processing of glomerular-filtered substances such as proteins, peptides, glucose, amino acids, uric acid, sodium, potassium, phosphate, and water via apical membrane receptors, transporters, and channels; (2) uptake of substances such as protein-bound compounds via basolateral membrane transporters followed by metabolism or secretion 

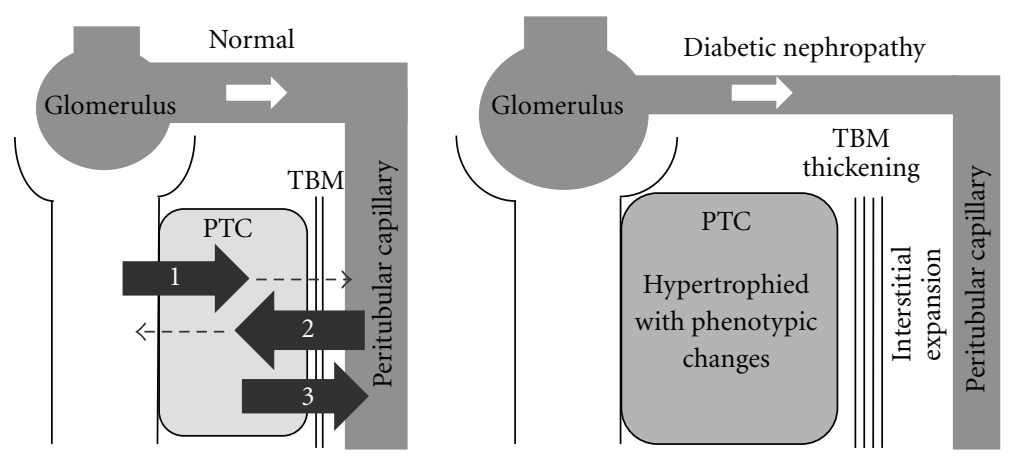

FIgURE 1: Normal functions of proximal tubule cells (PTCs) and structural changes around the cells in the early stages of diabetic nephropathy. Normal functions of PTCs include (1) reabsorption and intracellular processing of glomerular-filtered substances via apical membrane receptors, transporters, and channels; (2) uptake of substances via basolateral membrane transporters followed by metabolism or secretion into the urinary space; (3) synthesis of bioactive substances that are released to peritubular capillaries. These functions are impaired in diabetic nephropathy even at the early stages in which PTCs are hypertrophied with increased metabolic demands and are phenotypically altered. In addition, tubular basement membranes (TBMs) are thickened, and interstitial spaces are expanded with fibrosis, alienating PTCs from interacting with peritubular capillaries.

to the urinary space; (3) synthesis of substances that are released to the peritubular capillaries (Figure 1). Impairment of these diverse functions is likely to affect systemic hemodynamic and metabolic homeostasis and may mediate the development of CVD as discussed below.

\section{Dysfunction of PTCs in Diabetic Nephropathy}

In the early stages of diabetic nephropathy, PTCs are hypertrophied because of increased metabolic demands and phenotypically changed to express cytokines or chemokines [4]. Tubular basement membranes are thickened and interstitial spaces are expanded with fibrosis, isolating the PTCs from interaction with peritubular capillaries (Figure 1). Such structural changes and increased metabolic demands on PTCs are likely to cause ischemia in the cells. At more advanced stages, interstitial fibrosis is increased, peritubular capillaries become dispersed, and PTCs undergo atrophy, which further diminishes interaction between the cells and surrounding capillaries. Similar phenotypic changes of PTCs are also observed in patients with obesity or metabolic syndrome. In other glomerular diseases, tubulointerstitial damage also follows as a final common pathway for progression to ESRD [5].

\section{Megalin and Cubilin: Two Endocytic Receptors in Apical PTC Membranes}

Glomerular-filtered substances are reabsorbed by megalin and cubilin, two endocytic receptors expressed in apical PTC membranes (Figure 2). Megalin is a large $(\sim 600 \mathrm{kDa})$ glycoprotein member of the low-density lipoprotein receptor family $[6,7]$ that is primarily expressed in clathrin-coated pits [8]. Megalin-ligand complexes are internalized by invagination of clathrin-coated pits mediated by multiple adaptor proteins and motor molecules, forming endosomal vesicles. Acidification of the intravesicular lumen dissociates the ligands from megalin, and they are transported to lysosomes for degradation or storage, or secreted into the cytosol for further processing or transport. Megalin is recycled to the apical membranes through a recycling compartment. Megalin thus plays a critical role in reabsorption and metabolism of glomerular-filtered substances including albumin and low molecular weight proteins. Megalin knockout mice display low molecular weight proteinuria and albuminuria [9]. Furthermore, patients with Donnai-Barrow and facio-oculo-acoustico-renal syndromes, caused by mutations in the megalin gene, show increased urinary excretion of albumin and low molecular weight proteins [10].

Cubilin is a $460 \mathrm{kDa}$ peripheral glycoprotein that lacks transmembrane and intracellular segments but is anchored to apical membranes in PTCs. It was originally identified as the receptor for intrinsic factor-vitamin $B_{12}$ complex $[11,12]$. Cubilin gene defects are the cause of hereditary megaloblastic anaemia 1 or Imerslund-Gräsbeck syndrome, known as selective vitamin $B_{12}$ malabsorption with proteinuria [13]. Cubilin is also involved in the absorption of various protein ligands present in glomerular filtrates, including albumin, transferrin, and vitamin D-binding protein (DBP) [8]. Cubilin requires interaction with megalin to regulate its endocytic functions $[14,15]$; however, it is bound more firmly by a protein called amnionless, forming a complex named CUBAM [16, 17] (Figure 2). Amnionless, a 38$50 \mathrm{kDa}$ membrane protein with a single-transmembrane domain, was initially identified as a component required for normal development of the trunk mesoderm derived from the middle streak [18]. In addition, defects of the amnionless gene cause hereditary megaloblastic anaemia [19].

\section{Impaired Reabsorption of Glomerular-Filtered Substances via Megalin and Cubilin in Diabetic Nephropathy}

Decreased megalin expression in PTCs has been found in the early diabetic stages of experimental animals $[20,21]$. 


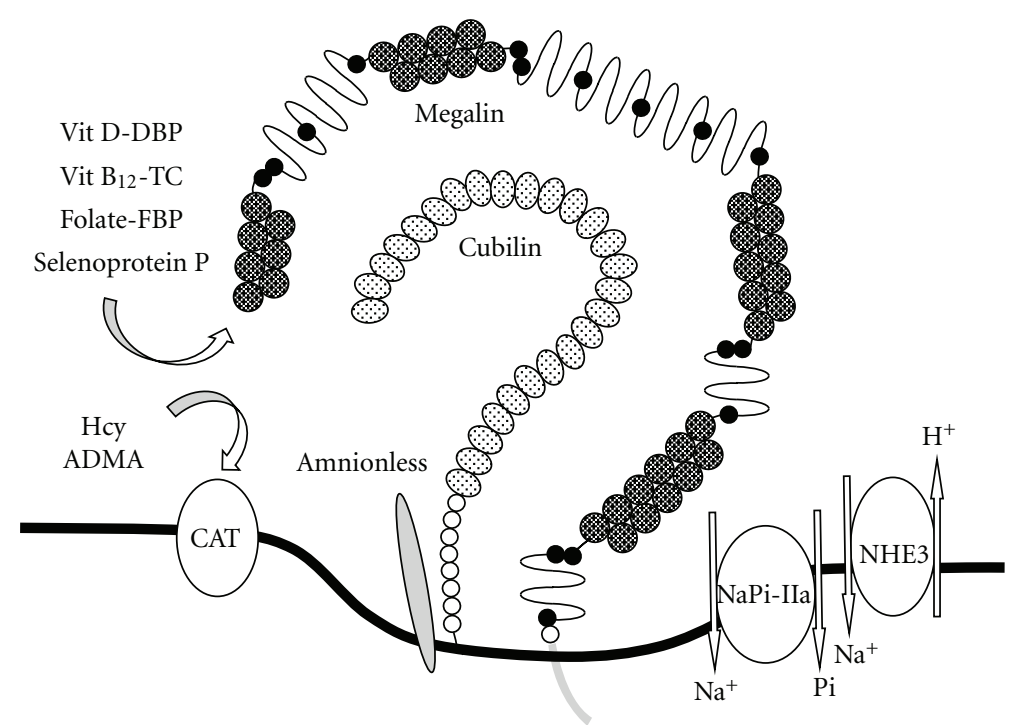

Figure 2: Endocytic receptors and transporters involved in the uptake of substances at the apical membranes of proximal tubule cells (PTCs). At apical membranes of PTCs, megalin and the cubilin-amnionless complex are involved in endcytosis of protein ligands. Megalin facilitates uptake of various ligands including vitamin D/vitamin D-binding protein (DBP), vitamin $\mathrm{B}_{12} /$ transcobalamin (TC), folate/folatebinding protein (FBP) complexes, and selenoprotein P. Similarly, cubilin facilitates uptake of the vitamin D/DBP complex. Type IIa $\mathrm{Na} / \mathrm{Pi}$ cotransporter (NaPi-IIa) and $\mathrm{Na}^{+} / \mathrm{H}^{+}$exchanger isoform 3 (NHE3) are primarily involved in the uptake of phosphate and sodium, respectively. Homocysteine (Hcy) and asymmetric dimethylarginine (ADMA) may be taken up by cationic amino acid transporters (CATs) and metabolized in PTCs. Dysregulation of the uptake or metabolism of these substances in PTCs in patients with CKD, especially with diabetic nephropathy, is likely to be involved in the mechanism that promotes the development of CVD.

It has also been suggested that the functions of megalin are impaired in patients during the early stages of diabetic nephropathy, since low molecular weight proteinuria is frequently observed in patients at these stages [22, 23]. Therefore, the altered regulation of megalin expression and its functions must be responsible for the early development of proteinuria/albuminuria in diabetic patients. The functions of cubilin, a direct receptor for albumin, may also be impaired in the early stages of diabetic nephropathy as urinary excretion of transferrin, another endocytic ligand of cubilin, is significantly increased in patients at the early stages [24]. The functions of both megalin and cubilin are likely to be further affected as tubulointerstitial injury in CKD progresses.

Cellular expression of megalin was found to be downregulated by TGF- 3 [21]. We also found that megalin expression in cultured PTCs is upregulated following treatment with insulin or high-concentration glucose. Conversely, it is downregulated by angiotensin II [25]. Furthermore, we demonstrated that there is competitive crosstalk between angiotensin II type 1 receptor- and insulin-mediated signaling pathways in the regulation of megalin expression in the cells [25]. Anigotensin II may be a major factor in suppressing megalin expression in the early stages of diabetic nephropathy since intrarenal RAS is activated in the disease [26].

Decreased expression or functioning of megalin and/or cubilin results in reduced reabsorption of their glomerularfiltered ligands. Impaired reabsorption of some ligands of these receptors may be associated with the development of CVD, as described next.

\section{Megalin- or Cubilin-Mediated Endocytic Ligands That May Promote Development of CVD When Depleted}

6.1. Vitamin D. Megalin and cubilin take up the $25(\mathrm{OH}) \mathrm{D}_{3} /$ DBP complex from glomerular filtrates [27, 28] (Figure 2). In PTCs, $25(\mathrm{OH}) \mathrm{D}_{3}$ is dissociated from DBP and converted by $1 \alpha$-hydroxylase to $1,25(\mathrm{OH})_{2} \mathrm{D}_{3}$, a biologically active form, which is released to the peritubular capillaries. Therefore, dysfunction of these endocytic receptors is an important cause of deficiency of both $25(\mathrm{OH}) \mathrm{D}_{3}$ and $1,25(\mathrm{OH})_{2} \mathrm{D}_{3}$ in $\mathrm{CKD}$ in addition to other factors such as decreased $1 \alpha$-hydroxylase activity. Vitamin D deficiency develops very early in the course of CKD, especially in diabetic nephropathy, and is associated with the development of CVD or mortality in patients at predialysis stages $[29,30]$. Treatment with the activated vitamin D analogue calcitriol was significantly associated with improved survival of patients with CKD $[31,32]$. In addition, vitamin D deficiency may also be associated with an increased risk of CVD in the general population [33], although the effects of vitamin D supplementation on the CVD-related mortality in the population remain controversial.

Many studies have investigated vitamin D deficiencyassociated mechanisms of vascular calcification and cardiac dysfunction. Vitamin D acts on vascular smooth muscle cells 


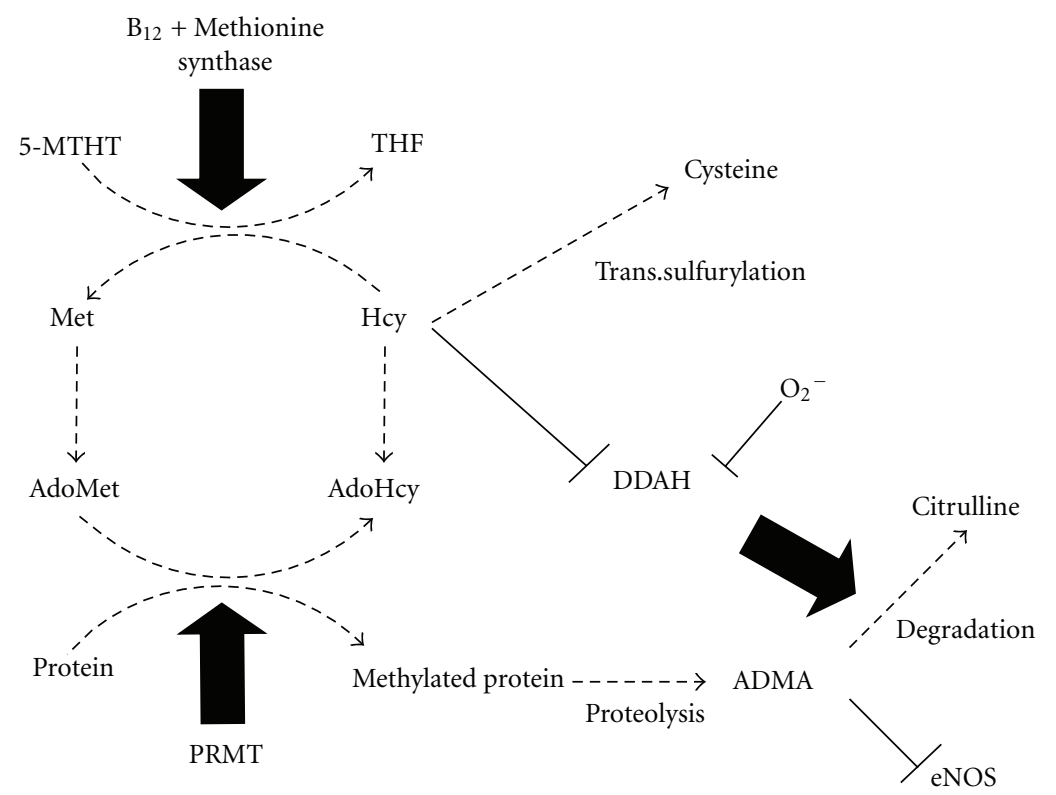

FIGURE 3: Intracellular synthesis and metabolism of homocysteine (Hcy) and asymmetric dimethylarginine (ADMA) and their biochemical link. Vitamin $\mathrm{B}_{12}$ serves as a cofactor for the formation of methionine (Met) from homocysteine (Hcy) by methionine synthase using 5methyl-tetrahydrofolate (5-MTHF), the dominant folate form in serum. S-adenosylmethionine (AdoMet) is the intermediate in this reaction and serves as the methyl donor to form S-adenosylhomocysteine (AdoHcy). Hcy is either remethylated to Met or transsulfurated to cysteine. Asymmetric dimethylarginine (ADMA) is an endogenous competitive inhibitor of endothelial nitric oxide synthase (eNOS). ADMA is formed by methylation of arginine residues in proteins with protein methyltransferase (PRMT) and released after proteolysis. Metabolism of ADMA is mediated by dimethylarginine dimethylaminohydrolases (DDAHs), which are downregulated by reactive oxygen species and Hcy.

to inhibit activators of vascular calcification, such as core binding factor-1 (Cbfa1), bone morphogenic protein-2, type I collagen, interleukin-1b, interleukin-6, and transforming growth factor- $\beta$, and to stimulate inhibitors of vascular calcification, such as matrix Gla protein and osteopontin [30]. Furthermore, decreased vitamin D-receptor activity increases circulating renin levels and blood pressure which results in left ventricular and myocyte hypertrophy [34].

6.2. Vitamin $B_{12}$ and Folate. Vitamin $B_{12}$ is a cofactor involved in the formation of methionine (Met) from homocysteine (Hcy) by cytoplasmic methionine synthase using 5-methyl-tetrahydrofolate (5-MTHF), the dominant folate form in serum, as a one-carbon donor [35] (Figure 3). Therefore, vitamin $\mathrm{B}_{12}$ and/or folate deficiency results in the accumulation of Hcy that is associated with the development of CVD. Following absorption from the intestine with intrinsic factor, vitamin $B_{12}$ is bound in the serum with transcobalamin, a $45 \mathrm{kDa}$ serum protein, for transport to target tissues. The transcobalamin-vitamin $\mathrm{B}_{12}$ complex is filtered by glomeruli and reabsorbed by megalin in PTCs [36] (Figure 2 ), which explains why vitamin $B_{12}$ deficiency can be induced by decreased megalin function.

Folate binds to a carrier protein termed folate-binding protein and also to other proteins including albumin. Alternatively, it exists in free form in serum. After being filtered by glomeruli, protein-bound folate is reabsorbed by PTCs through megalin-mediated endocytosis while the free form is likely taken up by folate receptors [37] (Figure 2).
Dysfunction of PTCs therefore results in decreased renal retrieval of folate, which subsequently leads to its deficiency.

6.3. Selenoprotein P. Megalin is also involved in the reabsorption of selenoprotein $\mathrm{P}$, a selenium-carrier protein from glomerular filtrates [38, 39] (Figure 2). Selenium is released from selenoprotein $\mathrm{P}$ and used in PTCs to synthesize glutathione peroxidase 3 (GPx3), a major plasma antioxidant enzyme [40]. GPx3 is involved in maintaining the vascular bioavailability of nitric oxide, a major vasorelaxant, as well as inhibiting platelet function [41]. Therefore, reduced uptake of selenoprotein P in PTCs due to impaired megalin function may result in decreased GPx3 synthesis which may be associated with the development of vascular diseases. Notably, a recent proteome analysis revealed that serum GPx3 levels are significantly decreased in patients at the microalbuminuric stage of type 2 diabetes and even further at the progressive stages [42]. In fact, familial GPx3 deficiency has been associated with an increased risk of childhood stroke $[43,44]$. Also, there have been reports that demonstrate decreased GPx 3 activity among patients with coronary artery disease, supporting a broader effect of this defect in the vascular system [45-47].

\section{Increased Phosphate Reabsorption in PTCs}

Hyperphosphatemia is significantly associated with the development of CVD and high mortality in patients with CKD, independent of estimated creatinine clearance [48]. 
Inorganic phosphate appears to act directly on cultured vascular smooth muscle cells to express the osteogenic markers Cbfal and osteocalcin, with subsequent mineralization of the extracellular matrix [49]. Serum phosphate concentration is regulated by intestinal absorption from dietary phosphate intake, but more importantly, by glomerular filtration and reabsorption of phosphate via type II Na/Pi cotransporters ( $\mathrm{NaPi}$-IIa and $\mathrm{NaPi}$-IIc) in the apical membranes of PTCs. In particular, NaPi-IIa plays a central role in phosphate reabsorption in the kidney (Figure 2). The presence of hyperphosphatemic patients with CKD whose GFR is normal is well explained by a hypothesis that $\mathrm{Na} / \mathrm{Pi}$ cotransporters in PTCs may be inappropriately upregulated. The functions of NaPi-IIa are regulated by various hormones and hormone-like substances, such as parathyroid hormone, fibroblast growth factor 23, and Klotho that all downregulate $\mathrm{NaPi}-\mathrm{II} a$ and induce phosphaturia. Regulation of $\mathrm{NaPi}$ IIa is almost exclusively mediated via receptor-mediated endocytosis and lysosomal degradation of NaPi-IIa [50]. Because megalin mediates the endocytic pathway for degradation of NaPi-IIa [51], decreased megalin function may result in hypophosphaturia or hyperphosphatemia even in cases with normal GFR.

\section{Increased Sodium Reabsorption in PTCs}

Proximal tubular uptake of sodium is increased in patients with diabetic nephropathy [52-54] and metabolic syndrome $[55,56]$ and is associated with the development of hypertension, another potent factor for CVD [57]. $\mathrm{Na}^{+} / \mathrm{H}^{+}$exchanger isoform 3 (NHE3) is the main NHE isoform in PTCs and mediates isotonic reabsorption of approximately two-thirds of filtered $\mathrm{NaCl}$ and water, reabsorption of bicarbonate, and secretion of ammonium ions [58] (Figure 2). Enhanced NHE3 activity is assumed to play a leading role in increased sodium reabsorption in diabetes while intrarenal RAS activation is also thought to be involved in the process [26]. Increased action of sodium glucose cotransporter SGLT2 is yet another factor promoting increased sodium uptake in PTCs in diabetes [59].

\section{Impaired Metabolism of Vasculotoxic Substances Taken up via Apical Transporters/Receptors in PTCs}

9.1. Homocysteine $(\mathrm{Hcy})$. Hcy is a sulfhydryl amino acid formed by demethylation of Met (Figure 3). Sadenosylmethionine (AdoMet) is the intermediate in this reaction and serves as the methyl donor to form Sadenosylhomocysteine (AdoHcy). Hcy is either remethylated to Met or transsulfurated to cysteine. Approximately $75 \%$ of total plasma Hcy is bound to protein, primarily albumin, via a disulfide bond (bound $\mathrm{Hcy}$ ), while the remaining 25\% exists in a free-form unbound state (free Hcy) in humans.

When patients with extreme hyperhomocysteinemia due to genetic enzyme defects were found to suffer from premature atherosclerosis and venous thrombosis, Hcy was hypothesized to be a direct vasculotoxic agent [60]. Subsequently, it was shown that plasma Hcy is strongly associated with renal function, and that $85 \%-100 \%$ of ESRD patients have elevated Hcy levels [61]. Hyperhomocysteinemia is recognized as a risk marker for CVD in patients with ESRD unless their conditions are complicated with malnutrition or inflammation that induces hypoalbuminemia and apparent low plasma Hct levels [62, 63].

The kidney probably plays an important role in Hcy clearance and metabolism. It is highly likely that free Hcy is filtered by glomeruli and taken up via cationic amino acid transporters in the apical membranes of PTCs [64, 65] (Figure 2). However, renal uptake of Hcy derived from bound Hcy may be mediated by basolateral tubular transporters. It is therefore assumed that impaired uptake and/or metabolism of Hcy in PTCs are associated with hyperhomocysteinemia in patients with CKD or ESRD and the development of CVD.

Hyperhomocysteinemia is also associated with an increase in AdoHcy, which is considered another predictor of cardiovascular events. AdoHcy is a powerful competitive inhibitor of protein as well as DNA methyltransferases. Increased intracellular AdoHcy can be expected to result in hypomethylation of proteins and genes, which will in turn induce protein dysfunction and epigenetic dysregulation, respectively $[66,67]$.

9.2. Asymmetric Dimethylarginine (ADMA). ADMA, a naturally occurring $\mathrm{L}$-arginine analogue, is an endogenous competitive inhibitor of nitric oxide synthase and an important inducer of endothelial dysfunction. ADMA is formed by the methylation of arginine residues in peptides with protein methyltransferase (PRMT) and their release after proteolysis. In this reaction, AdoMet is the methyl donor, and AdoHcy is the demethylated product. Formations of ADMA and Hcy are therefore biochemically linked (Figure 3 ).

An increased plasma concentration of ADMA is associated with the development of CVD [68]. In patients with nondiabetic CKD, blood concentrations of ADMA are markedly increased at an early stage, even when GFR is still within the normal range [69]. Increased plasma ADMA levels are also closely associated with the development and progression of nephropathy in patients with type 2 diabetes [70].

The kidney is an important organ for clearance of ADMA $[71,72]$, which is eliminated from circulation by both renal excretion and metabolic degradation. Renal uptake of ADMA is very likely mediated by cationic amino acid transporters that are predominantly expressed in the apical membranes of PTCs [73]. ADMA metabolism is mediated by dimethylarginine dimethylaminohydrolases (DDAHs), which are posttranscriptionally downregulated by reactive oxygen species and Hcy $[74,75]$. Two isoforms of DDAH exist and are differentially localized and regulated. In the kidney, DDAH I is abundantly expressed in PTCs, while DDAH II is located in glomeruli, afferent arterioles, macula densa, and distal nephrons [76]. Recent studies have indicated that DDAH I is mainly involved in the regulation of plasma ADMA levels [77]. In addition, ADMA is formed by the activity of PRMT that is highly expressed in PTCs. In subtotally nephrectomized rats showing increased plasma ADMA 
levels, DDAH protein levels were decreased while expression of PRMT was increased in the kidney [78]. Such effects are likely to mediate the mechanism of increasing plasma ADMA levels. Streptozotocin-induced rat diabetic kidneys also showed decreased DDAH I expression, which was reversed by telmisartan, an angiotensin II-receptor blocker [76].

9.3. Advanced Glycation End Products (AGEs) and Free Adduct Glycation, Oxidation, and Nitration Products. Megalin mediates proximal tubular uptake of AGEs, a potent factor of vascular injury [79]. It remains unclear how effectively AGEs are metabolized in PTCs, but this metabolic process may be affected in damaged PTCs. AGE precursors which include glycation, oxidation, and nitration free adducts are also excreted or metabolized in the kidney [80]. Methylglyoxal, one such dicarbonyl adduct, is a potent glycating agent associated with oxidative stress and vascular injury [81] and is increased in the serum of patients with CKD or uremia, probably because of reduced renal metabolism [80]. Methylglyoxal is metabolized by glyoxalase I that is usually expressed in PTCs but is downregulated in the rat model of renal injury [82]. This suggests that decreased enzymatic activities in PTCs may be a cause of increased serum methylglyoxal in CKD.

\section{Impaired Uptake, Metabolism, or Urinary Excretion of Vasculotoxic Substances via Basolateral PTC Transporters in PTCs}

10.1. Indoxyl Sulfate and Other Protein-Bound Uremic Toxins. Indoxyl sulfate is a protein-bound uremic toxin that results from the metabolism of dietary tryptophan. Increase of serum indoxyl sulfate in patients with CKD is associated with both the development of CVD and mortality [83]. Indoxyl sulfate is excreted in urine via the organic anion transporters OAT1 and OAT3 that are predominantly expressed in the basolateral membranes of PTCs [84]. These transporters are important as they are also involved in urinary excretion of other protein-bound uremic toxins such as 3-carboxy-4methyl-5-propyl-2-furanpropionate, indoleacetate, and hippurate, which may also be associated with the development of CVD in patients with CKD [85].

10.2. Guanidino Succinate, Transaconitate, and ADMA. SLCO4C1 is a human kidney-specific organic anion transporting polypeptide that was first identified as a digoxin transporter [86]. In renal failure, basolateral SLCO4C1 expression in PTCs is decreased; however, the expression level of multidrug resistance protein 1 that mediates the tubular secretion of digoxin in the apical membranes of PTCs is not changed [86]. A kidney-specific transgenic rat line overexpressing human SLCO4C1 in PTCs was shown to significantly eliminate the uremic toxins guanidino succinate and trans-aconitate as well as ADMA from circulation, even when renal failure was induced by 5/6 nephrectomy [87]. In this study, pravastatin was also found to upregulate the expression of SLCO4C1 and facilitate the removal of circulating ADMA.

\section{Decreased Synthesis of Vasculoprotective Substances by PTCs}

As mentioned earlier, vasculoprotective substances such as $1,25(\mathrm{OH})_{2} \mathrm{D}_{3}$ and $\mathrm{GPx} 3$ are synthesized by PTCs and secreted into circulation. In addition, renalase, a circulating monoamine oxidase, is a similar substance that is synthesized by the PTCs and regulates various cardiac functions and blood pressure [88]. Plasma concentrations of these factors are reduced in patients with CKD most likely because of decreased synthesis in the PTCs.

\section{Therapeutic Strategies for Targeting PTC Dysfunction}

Given the diverse and complex functions of PTCs, it is important to establish comprehensive therapeutic strategies to preserve PTC viability and maintain their broad range of functions in diabetic nephropathy and other disorders related to CKD. Therefore, it may not be sufficient to compensate only for specific functions of the cells; in fact, such an approach may explain why the outcomes of recent supplemental trials that used vitamin $\mathrm{B}_{12}$ and folate to target Hcy levels were controversial $[89,90]$. In addition, vitamin $\mathrm{B}_{12}$ and folate deficiencies due to decreased PTC uptake may be masked by reduced GFR in advanced stages of CKD. Therefore, supplementation with these vitamins could lead to overdose and adverse side effects. Inhibitors of the reninangiotensin II system and statins may effectively alleviate PTC dysfunction; however, the mechanisms of these agents acting on PTCs remain to be elucidated as the phenotypes or pharmacological responsiveness of PTCs may change according to pathogenic stages. Therefore, it is also necessary to develop effective biomarkers to evaluate and monitor the stages of PTC dysfunction.

\section{Conclusions}

Dysregulation of PTC functions is likely to mediate the multifactorial mechanisms of the development of CVD as well as progression to ESRD and therefore plays a role in cardiorenal syndrome. In particular, PTC dysfunction occurs at the early stages of diabetic nephropathy, a leading cause of CKD. It is important to elucidate the mechanisms of PTC dysfunction and establish therapeutic strategies that protect against PTC dysregulation.

\section{Acknowledgment}

This work was supported by a Grant-in-Aid for Scientific Research from the Ministry of Education, Science, and Culture of Japan (no. 21591023).

\section{References}

[1] H. C. Gerstein, J. F. E. Mann, Q. Yi et al., "Albuminuria and risk of cardiovascular events, death, and heart failure in diabetic and nondiabetic individuals," Journal of the American Medical Association, vol. 286, no. 4, pp. 421-426, 2001. 
[2] K. Wachtell, H. Ibsen, M. H. Olsen et al., "Albuminuria and cardiovascular risk in hypertensive patients with left ventricular hypertrophy: the LIFE study," Annals of Internal Medicine, vol. 139, no. 11, pp. 901-906, 2003.

[3] "KDIGO clinical practice guideline for the diagnosis, evaluation, prevention, and treatment of Chronic Kidney DiseaseMineral and Bone Disorder (CKD-MBD)," Kidney International, vol. 113, pp. S1-S130, 2009.

[4] M. C. Thomas, W. C. Burns, and M. E. Cooper, "Tubular changes in early diabetic nephropathy," Advances in Chronic Kidney Disease, vol. 12, no. 2, pp. 177-186, 2005.

[5] M. Nangaku, "Chronic hypoxia and tubulointerstitial injury: a final common pathway to end-stage renal failure," Journal of the American Society of Nephrology, vol. 17, no. 1, pp. 17-25, 2006.

[6] A. Saito, S. Pietromonaco, A. K. C. Loo, and M. G. Farquhar, "Complete cloning and sequencing of rat gp330/"megalin," a distinctive member of the low density lipoprotein receptor gene family," Proceedings of the National Academy of Sciences of the United States of America, vol. 91, no. 21, pp. 9725-9729, 1994.

[7] G. Hjälm, E. Murray, G. Crumley et al., "Cloning and sequencing of human gp330, a $\mathrm{Ca}^{2+}$-binding receptor with potential intracellular signaling properties," European Journal of Biochemistry, vol. 239, no. 1, pp. 132-137, 1996.

[8] E. I. Christensen, P. J. Verroust, and R. Nielsen, "Receptormediated endocytosis in renal proximal tubule," Pflugers Archiv European Journal of Physiology, vol. 458, no. 6, pp. 1039-1048, 2009.

[9] J. R. Leheste, B. Rolinski, H. Vorum et al., "Megalin knockout mice as an animal model of low molecular weight proteinuria," American Journal of Pathology, vol. 155, no. 4, pp. 1361-1370, 1999.

[10] S. Kantarci, L. Al-Gazali, R. S. Hill et al., "Mutations in LRP2, which encodes the multiligand receptor megalin, cause Donnai-Barrow and facio-oculo-acoustico-renal syndromes," Nature Genetics, vol. 39, no. 8, pp. 957-959, 2007.

[11] B. Seetharam, J. S. Levine, M. Ramasamy, and D. H. Alpers, "Purification, properties, and immunochemical localization of a receptor for intrinsic factor-cobalamin complex in the rat kidney," Journal of Biological Chemistry, vol. 263, no. 9, pp. 4443-4449, 1988.

[12] B. Seetharam, E. I. Christensen, S. K. Moestrup, T. G. Hammond, and P. J. Verroust, "Identification of rat yolk sac target protein of teratogenic antibodies, gp280, as intrinsic factor-cobalamin receptor," Journal of Clinical Investigation, vol. 99, no. 10, pp. 2317-2322, 1997.

[13] M. Aminoff, JO. E. Carter, R. B. Chadwick et al., "Mutations in CUBN, encoding the intrinsic factor-vitamin $\mathrm{B}$ receptor, cubilin, cause hereditary megaloblastic anaemia 1," Nature Genetics, vol. 21, no. 3, pp. 309-313, 1999.

[14] R. R. Yammani, S. Seetharam, and B. Seetharam, "Identification and characterization of two distinct ligand binding regions of cubilin," Journal of Biological Chemistry, vol. 276, no. 48, pp. 44777-44784, 2001.

[15] R. Kozyraki, J. Fyfe, P. J. Verroust et al., "Megalin-dependent cubilin-mediated endocytosis is a major pathway for the apical uptake of transferrin in polarized epithelia," Proceedings of the National Academy of Sciences of the United States of America, vol. 98, no. 22, pp. 12491-12496, 2001.

[16] J. C. Fyfe, M. Madsen, P. Højrup et al., "The functional cobalamin (vitamin $\mathrm{B}_{12}$ )-intrinsic factor receptor is a novel complex of cubilin and amnionless," Blood, vol. 103, no. 5, pp. 1573-1579, 2004.
[17] G. Coudroy, J. Gburek, R. Kozyraki et al., "Contribution of cubilin and amnionless to processing and membrane targeting of cubilin-amnionless complex," Journal of the American Society of Nephrology, vol. 16, no. 8, pp. 2330-2337, 2005.

[18] S. Kalantry, S. Manning, O. Haub et al., "The amnionless gene, essential for mouse gastrulation, encodes a visceralendoderm-specific protein with an extracellular cysteinerich domain," Nature Genetics, vol. 27, no. 4, pp. 412-416, 2001.

[19] S. M. Tanner, M. Aminoff, F. A. Wright et al., "Amnionless, essential for mouse gastrulation, is mutated in recessive hereditary megaloblastic anemia," Nature Genetics, vol. 33, no. 3, pp. 426-429, 2003.

[20] A. Tojo, M. Onozato, H. Ha et al., "Reduced albumin reabsorption in the proximal tubule of early-stage diabetic rats," Histochemistry and Cell Biology, vol. 116, no. 3, pp. 269276, 2001.

[21] L. M. Russo, E. Del Re, D. Brown, and H. Y. Lin, "Evidence for a role of transforming growth factor (TGF)- $\beta 1$ in the induction of postglomerular albuminuria in diabetic nephropathy: amelioration by soluble TGF- $\beta$ type II receptor," Diabetes, vol. 56, no. 2, pp. 380-388, 2007.

[22] P. Pontuch, T. Jensen, T. Deckert, P. Ondrejka, and M. Mikulecky, "Urinary excretion of retinol-binding protein in type 1 (insulin-dependent) diabetic patients with microalbuminuria and clinical diabetic nephropathy," Acta Diabetologica, vol. 28, no. 3-4, pp. 206-210, 1992.

[23] C. Y. Hong, K. Hughes, K. S. Chia, V. Ng, and S. L. Ling, "Urinary $\alpha$-microglobulin as a marker of nephropathy in type 2 diabetic Asian subjects in Singapore," Diabetes Care, vol. 26, no. 2, pp. 338-342, 2003.

[24] M. Kanauchi, Y. Akai, and T. Hashimoto, "Transferrinuria in type 2 diabetic patients with early nephropathy and tubulointerstitial injury," European Journal of Internal Medicine, vol. 13, no. 3, pp. 190-193, 2002.

[25] M. Hosojima, H. Sato, K. Yamamoto et al., "Regulation of megalin expression in cultured proximal tubule cells by angiotensin II type $1 \mathrm{~A}$ receptor- and insulin-mediated signaling cross talk," Endocrinology, vol. 150, no. 2, pp. 871878, 2009.

[26] H. Kobori, M. Nangaku, L. G. Navar, and A. Nishiyama, "The intrarenal renin-angiotensin system: From physiology to the pathobiology of hypertension and kidney disease," Pharmacological Reviews, vol. 59, no. 3, pp. 251-287, 2007.

[27] A. Nykjaer, D. Dragun, D. Walther et al., "An endocytic pathway essential for renal uptake and activation of the steroid 25-(OH) vitamin D," Cell, vol. 96, no. 4, pp. 507-515, 1999.

[28] A. Nykjaer, J. C. Fyfe, R. Kozyraki et al., "Cubilin dysfunction causes abnormal metabolism of the steroid hormone $25(\mathrm{OH})$ vitamin $\mathrm{D}_{3}$," Proceedings of the National Academy of Sciences of the United States of America, vol. 98, no. 24, pp. 13895-13900, 2001.

[29] R. Mehrotra, D. A. Kermah, I. B. Salusky et al., "Chronic kidney disease, hypovitaminosis $\mathrm{D}$, and mortality in the United States," Kidney International, vol. 76, no. 9, pp. 977983, 2009.

[30] A. Gal-Moscovici and S. M. Sprague, "Use of vitamin D in chronic kidney disease patients," Kidney International, vol. 78, no. 2, pp. 146-151, 2010.

[31] A. B. Shoben, K. D. Rudser, I. H. de Boer, B. Young, and B. Kestenbaum, "Association of oral calcitriol with improved survival in nondialyzed CKD," Journal of the American Society of Nephrology, vol. 19, no. 8, pp. 1613-1619, 2008. 
[32] C. P. Kovesdy, S. Ahmadzadeh, J. E. Anderson, and K. Kalantar-Zadeh, "Association of activated vitamin D treatment and mortality in chronic kidney disease," Archives of Internal Medicine, vol. 168, no. 4, pp. 397-403, 2008.

[33] H. H. Swales and T. J. Wang, "Vitamin D and cardiovascular disease risk: emerging evidence," Current Opinion in Cardiology, vol. 25, no. 5, pp. 513-517, 2010.

[34] W. Xiang, J. Kong, S. Chen et al., "Cardiac hypertrophy in vitamin D receptor knockout mice: role of the systemic and cardiac renin-angiotensin systems," American Journal of Physiology, vol. 288, no. 1, pp. E125-E132, 2005.

[35] H. Birn, "The kidney in vitamin $B_{12}$ and folate homeostasis: characterization of receptors for tubular uptake of vitamins and carrier proteins," American Journal of Physiology, vol. 291, no. 1, pp. F22-F36, 2006.

[36] H. Birn, T. E. Willnow, R. Nielsen et al., "Megalin is essential for renal proximal tubule reabsorption and accumulation of transcobalamin- $\mathrm{B}_{12}$," American Journal of Physiology, vol. 282, no. 3, pp. F408-F416, 2002.

[37] A. C. Antony, "The biological chemistry of folate receptors," Blood, vol. 79, no. 11, pp. 2807-2820, 1992.

[38] G. E. Olson, V. P. Winfrey, K. E. Hill, and R. F. Burk, “Megalin mediates selenoprotein $\mathrm{p}$ uptake by kidney proximal tubule epithelial cells," Journal of Biological Chemistry, vol. 283, no. 11, pp. 6854-6860, 2008.

[39] J. Chiu-Ugalde, F. Theilig, T. Behrends et al., "Mutation of megalin leads to urinary loss of selenoprotein $\mathrm{P}$ and selenium deficiency in serum, liver, kidneys and brain," Biochemical Journal, vol. 431, no. 1, pp. 103-111, 2010.

[40] R. F. Burk and K. E. Hill, "Selenoprotein P-expression, functions, and roles in mammals," Biochimica et Biophysica Acta, vol. 1790, no. 11, pp. 1441-1447, 2009.

[41] J. C. Whitin, S. Bhamre, D. M. Tham, and H. J. Cohen, "Extracellular glutathione peroxidase is secreted basolaterally by human renal proximal tubule cells," American Journal of Physiology, vol. 283, no. 1, pp. F20-F28, 2002.

[42] H. J. Kim, E. H. Cho, JI. H. Yoo et al., "Proteome analysis of serum from type 2 diabetics with nephropathy," Journal of Proteome Research, vol. 6, no. 2, pp. 735-743, 2007.

[43] J. E. Freedman, J. Loscalzo, S. E. Benoit, C. R. Valeri, M. R. Barnard, and A. D. Michelson, "Decreased platelet inhibition by nitric oxide in two brothers with a history of arterial thrombosis," Journal of Clinical Investigation, vol. 97, no. 4, pp. 979-987, 1996.

[44] G. Kenet, J. Freedman, B. Shenkman et al., "Plasma glutathione peroxidase deficiency and platelet insensitivity to nitric oxide in children with familial stroke," Arteriosclerosis, Thrombosis, and Vascular Biology, vol. 19, no. 8, pp. 20172023, 1999.

[45] C. C. K. Chao, Y. T. Huang, C. M. Ma, W. Y. Chou, and S. Lin-Chao, "Overexpression of glutathione S-transferase and elevation of thiol pools in a multidrug-resistant human colon cancer cell line," Molecular Pharmacology, vol. 41, no. 1, pp. 69-75, 1992.

[46] S. Doğru-Abbasoğlu, Ö. Kanbağli, H. Bulur et al., "Lipid peroxides and antioxidant status in serum of patients with angiographically defined coronary atherosclerosis," Clinical Biochemistry, vol. 32, no. 8, pp. 671-672, 1999.

[47] V. Muzáková, R. Kandár, P. Vojtísek, J. Skalický, and Z. Cervinková, "Selective antioxidant enzymes during ischemia/reperfusion in myocardial infarction," Physiological Research, vol. 49, no. 3, pp. 315-322, 2000.
[48] B. Kestenbaum, J. N. Sampson, K. D. Rudser et al., "Serum phosphate levels and mortality risk among people with chronic kidney disease," Journal of the American Society of Nephrology, vol. 16, no. 2, pp. 520-528, 2005.

[49] C. M. Giachelli, S. Jono, A. Shioi, Y. Nishizawa, K. Mori, and H. Morii, "Vascular calcification and inorganic phosphate," American Journal of Kidney Diseases, vol. 38, no. 4, pp. S34S37, 2001.

[50] S. Amatschek, M. Haller, and R. Oberbauer, "Renal phosphate handling in human-what can we learn from hereditary hypophosphataemias?" European Journal of Clinical Investigation, vol. 40, no. 6, pp. 552-560, 2010.

[51] S. Bachmann, U. Schlichting, B. Geist et al., "Kidney-specific inactivation of the megalin gene impairs trafficking of renal inorganic sodium phosphate cotransporter (NaPi-IIa)," Journal of the American Society of Nephrology, vol. 15, no. 4, pp. 892-900, 2004.

[52] J. Ditzel, H. H. Lervang, and J. Brochner-Mortensen, "Renal sodium metabolism in relation to hypertension in diabetes," Diabete et Metabolisme, vol. 15, no. 5, pp. 292-295, 1989.

[53] P. Skott, E. R. Mathiesen, E. Hommel, M. A. Gall, N. E. Bruun, and H. H. Parving, "The increased proximal tubular reabsorption of sodium and water is maintained in longterm insulin-dependent diabetics with early nephropathy," Scandinavian Journal of Clinical and Laboratory Investigation, vol. 49, no. 5, pp. 419-425, 1989.

[54] G. Vervoort, B. Veldman, J. H. M. Berden, P. Smits, and J. F. M. Wetzels, "Glomerular hyperfiltration in type 1 diabetes mellitus results from primary changes in proximal tubular sodium handling without changes in volume expansion," European Journal of Clinical Investigation, vol. 35, no. 5, pp. 330-336, 2005.

[55] P. Strazzullo, G. Barba, F. P. Cappuccio et al., "Altered renal sodium handling in men with abdominal adiposity: a link to hypertension," Journal of Hypertension, vol. 19, no. 12, pp. 2157-2164, 2001.

[56] P. Strazzullo, A. Barbato, F. Galletti et al., "Abnormalities of renal sodium handling in the metabolic syndrome. Results of the Olivetti Heart Study," Journal of Hypertension, vol. 24, no. 8, pp. 1633-1639, 2006.

[57] F. P. Cappuccio, P. Strazzullo, A. Siani, and M. Trevisan, "Increased proximal sodium reabsorption is associated with increased cardiovascular risk in men," Journal of Hypertension, vol. 14, no. 7, pp. 909-914, 1996.

[58] I. A. Bobulescu and O. W. Moe, "Luminal $\mathrm{Na}^{+} / \mathrm{H}^{+}$exchange in the proximal tubule," Pflugers Archiv European Journal of Physiology, vol. 458, no. 1, pp. 5-21, 2009.

[59] V. Vallon and K. Sharma, "Sodium-glucose transport: role in diabetes mellitus and potential clinical implications," Hypertension, vol. 19, no. 5, pp. 425-431, 2010.

[60] K. S. McCully, "Vascular pathology of homocysteinemia: implications for the pathogenesis of arteriosclerosis," American Journal of Pathology, vol. 56, no. 1, pp. 111-128, 1969.

[61] C. van Guldener and C. D. A. Stehouwer, "Homocysteine metabolism in renal disease," Clinical Chemistry and Laboratory Medicine, vol. 41, no. 11, pp. 1412-1417, 2003.

[62] D. Ducloux, A. Klein, A. Kazory, N. Devillard, and J. M. Chalopin, "Impact of malnutrition-inflammation on the association between homocysteine and mortality," Kidney International, vol. 69, no. 2, pp. 331-335, 2006.

[63] M. Suliman, P. Stenvinkel, A. R. Qureshi et al., "The reverse epidemiology of plasma total homocysteine as a mortality risk 
factor is related to the impact of wasting and inflammation," Nephrology Dialysis Transplantation, vol. 22, no. 1, pp. 209217, 2007.

[64] J. W. Foreman, H. Wald, and G. Blumberg, "Homocystine uptake in isolated rat renal cortical tubules," Metabolism, vol. 31, no. 6, pp. 613-619, 1982.

[65] F. Verrey, D. Singer, T. Ramadan, R. N. Vuille-Dit-Bille, L. Mariotta, and S. M. R. Camargo, "Kidney amino acid transport," Pflugers Archiv European Journal of Physiology, vol. 458, no. 1, pp. 53-60, 2009.

[66] D. Ingrosso, A. Cimmino, A. F. Perna et al., "Folate treatment and unbalanced methylation and changes of allelic expression induced by hyperhomocysteinaemia in patients with uraemia," Lancet, vol. 361, no. 9370, pp. 1693-1699, 2003.

[67] D. Ingrosso and A. F. Perna, "Epigenetics in hyperhomocysteinemic states. A special focus on uremia," Biochimica et Biophysica Acta, vol. 1790, no. 9, pp. 892-899, 2009.

[68] S. Blackwell, "The biochemistry, measurement and current clinical significance of asymmetric dimethylarginine," Annals of Clinical Biochemistry, vol. 47, no. 1, pp. 17-28, 2010.

[69] J. T. Kielstein, R. H. Böger, S. M. Bode-Böger et al., "Marked increase of asymmetric dimethylarginine in patients with incipient primary chronic renal disease," Journal of the American Society of Nephrology, vol. 13, no. 1, pp. 170-176, 2002.

[70] KO. Hanai, T. Babazono, I. Nyumura et al., "Asymmetric dimethylarginine is closely associated with the development and progression of nephropathy in patients with type 2 diabetes," Nephrology Dialysis Transplantation, vol. 24, no. 6, pp. 1884-1888, 2009.

[71] R. J. Nijveldt, M. P. C. Siroen, T. Teerlink, and P. A. M. Van Leeuwen, "Elimination of asymmetric dimethylarginine by the kidney and the liver: a link to the development of multiple organ failure?" Journal of Nutrition, vol. 134, no. 10, pp. 2848S-2852S, 2004.

[72] T. Teerlink, "ADMA metabolism and clearance," Vascular Medicine, vol. 10, supplement 1, pp. S73-S81, 2005.

[73] T. Teerlink, Z. Luo, F. Palm, and C. S. Wilcox, "Cellular ADMA: regulation and action," Pharmacological Research, vol. 60, no. 6, pp. 448-460, 2009.

[74] SU. J. Jia, D. J. Jiang, C. P. Hu, X. H. Zhang, H. W. Deng, and Y. J. Li, "Lysophosphatidylcholine-induced elevation of asymmetric dimethylarginine level by the NADPH oxidase pathway in endothelial cells," Vascular Pharmacology, vol. 44, no. 3, pp. 143-148, 2006.

[75] N. Tyagi, K. C. Sedoris, M. Steed, A. V. Ovechkin, K. S. Moshal, and S. C. Tyagi, "Mechanisms of homocysteineinduced oxidative stress," American Journal of Physiology, vol. 289, no. 6, pp. H2649-H2656, 2005.

[76] M. L. Onozato, A. Tojo, J. Leiper, T. Fujita, F. Palm, and C. S. Wilcox, "Expression of N,N-dimethylarginine dimethylaminohydrolase and protein arginine $\mathrm{N}$-methyltransferase isoforms in diabetic rat kidney: effects of angiotensin II receptor blockers," Diabetes, vol. 57, no. 1, pp. 172-180, 2008.

[77] F. Palm, M. L. Onozato, Z. Luo, and C. S. Wilcox, "Dimethylarginine dimethylaminohydrolase (DDAH): expression, regulation, and function in the cardiovascular and renal systems," American Journal of Physiology, vol. 293, no. 6, pp. H3227H3245, 2007.

[78] K. Matsuguma, S. Ueda, S. I. Yamagishi et al., "Molecular mechanism for elevation of asymmetric dimethylarginine and its role for hypertension in chronic kidney disease," Journal of the American Society of Nephrology, vol. 17, no. 8, pp. 21762183, 2006.
[79] A. Saito, R. Nagai, A. Tanuma et al., "Role of megalin in endocytosis of advanced glycation end products: implications for a novel protein binding to both megalin and advanced glycation end products," Journal of the American Society of Nephrology, vol. 14, no. 5, pp. 1123-1131, 2003.

[80] N. Rabbani, K. Sebekova, K. Sebekova, A. Heidland, and P. J. Thornalley, "Accumulation of free adduct glycation, oxidation, and nitration products follows acute loss of renal function," Kidney International, vol. 72, no. 9, pp. 1113-1121, 2007.

[81] T. Chang and L. Wu, "Methylglyoxal, oxidative stress, and hypertension," Canadian Journal of Physiology and Pharmacology, vol. 84, no. 12, pp. 1229-1238, 2006.

[82] T. Kumagai, M. Nangaku, I. Kojima et al., "Glyoxalase I overexpression ameliorates renal ischemia-reperfusion injury in rats," American Journal of Physiology, vol. 296, no. 4, pp. F912-F921, 2009.

[83] F. C. Barreto, D. V. Barreto, S. Liabeuf et al., "Serum indoxyl sulfate is associated with vascular disease and mortality in chronic kidney disease patients," Clinical Journal of the American Society of Nephrology, vol. 4, no. 10, pp. 1551-1558, 2009.

[84] A. Enomoto, M. Takeda, A. Tojo et al., "Role of organic anion transporters in the tubular transport of indoxyl sulfate and the induction of its nephrotoxicity," Journal of the American Society of Nephrology, vol. 13, no. 7, pp. 1711-1720, 2002.

[85] T. Deguchi, H. Kusuhara, A. Takadate, H. Endou, M. Otagiri, and Y. Sugiyama, "Characterization of uremic toxin transport by organic anion transporters in the kidney," Kidney International, vol. 65, no. 1, pp. 162-174, 2004.

[86] T. Mikkaichi, T. Suzuki, T. Onogawa et al., "Isolation and characterization of a digoxin transporter and its rat homologue expressed in the kidney," Proceedings of the National Academy of Sciences of the United States of America, vol. 101, no. 10, pp. 3569-3574, 2004.

[87] T. Toyohara, T. Suzuki, R. Morimoto et al., "SLCO4C1 transporter eliminates uremic toxins and attenuates hypertension and renal inflammation," Journal of the American Society of Nephrology, vol. 20, no. 12, pp. 2546-2555, 2009.

[88] J. Xu, G. Li, P. Wang et al., "Renalase is a novel, soluble monoamine oxidase that regulates cardiac function and blood pressure," Journal of Clinical Investigation, vol. 115, no. 5, pp. 1275-1280, 2005.

[89] C. Antoniades, A. S. Antonopoulos, D. Tousoulis, K. Marinou, and C. Stefanadis, "Homocysteine and coronary atherosclerosis: from folate fortification to the recent clinical trials," European Heart Journal, vol. 30, no. 1, pp. 6-15, 2009.

[90] P. J. Thornalley and N. Rabbani, "Therapy: vitamin $\mathrm{B}_{6}, \mathrm{~B}_{9}$ and $\mathrm{B}_{12}$ in diabetic nephropathy-beware," Nature Reviews Endocrinology, vol. 6, no. 9, pp. 477-478, 2010. 


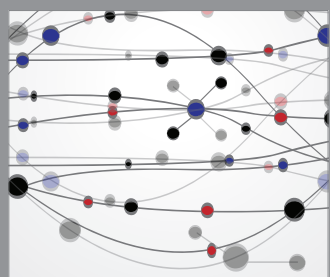

The Scientific World Journal
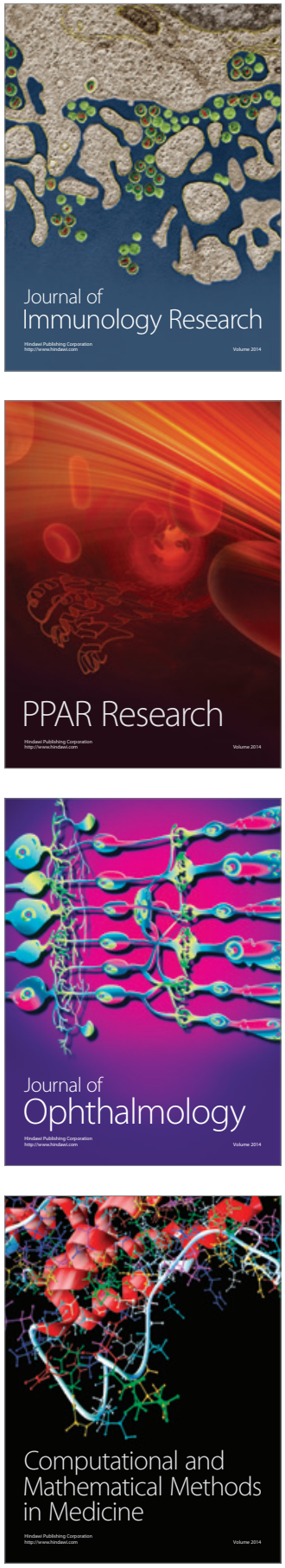

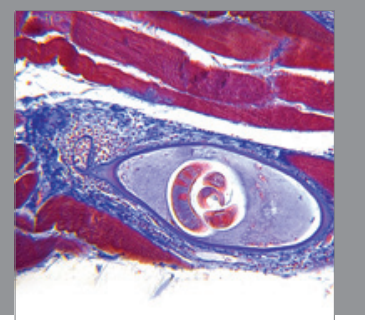

Gastroenterology

Research and Practice
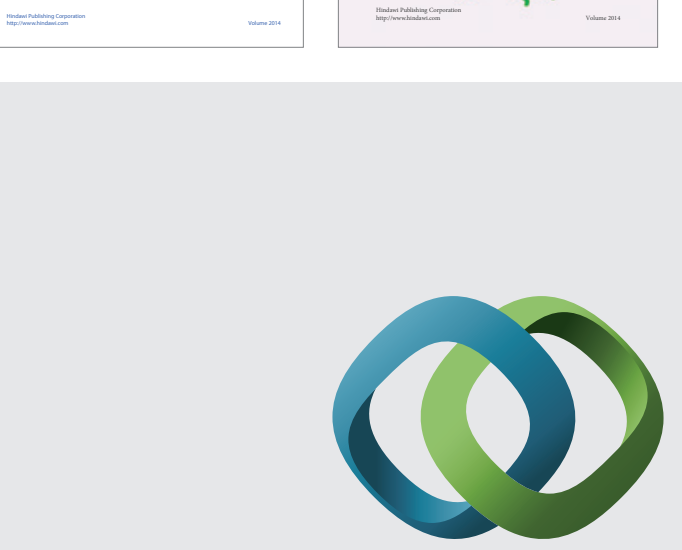

\section{Hindawi}

Submit your manuscripts at

http://www.hindawi.com
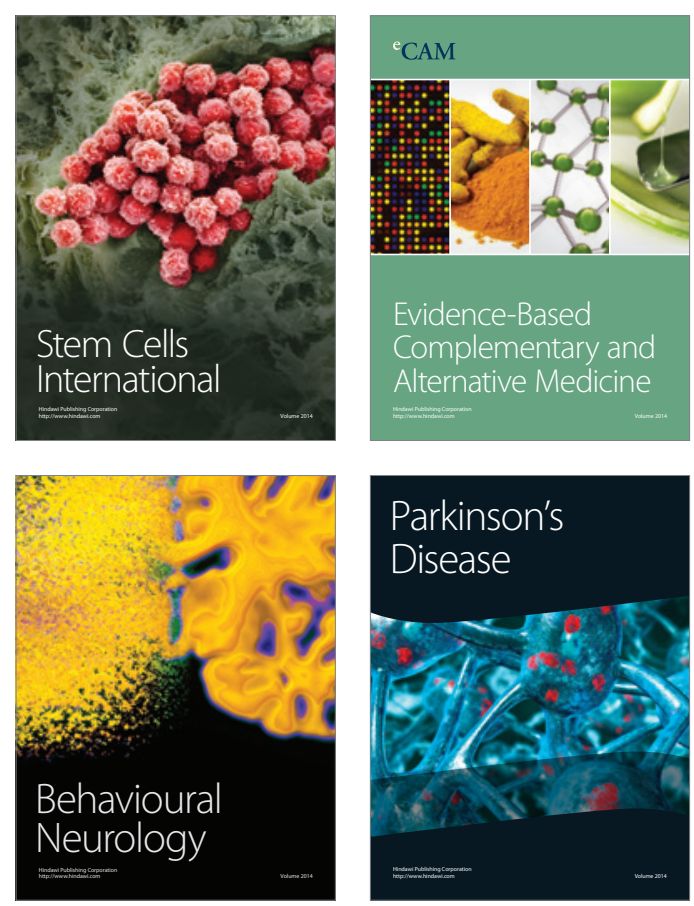

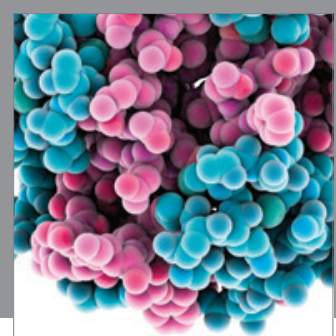

Journal of
Diabetes Research

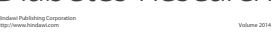

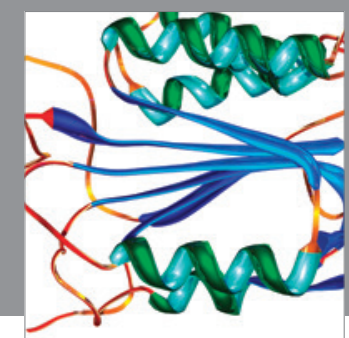

Disease Markers
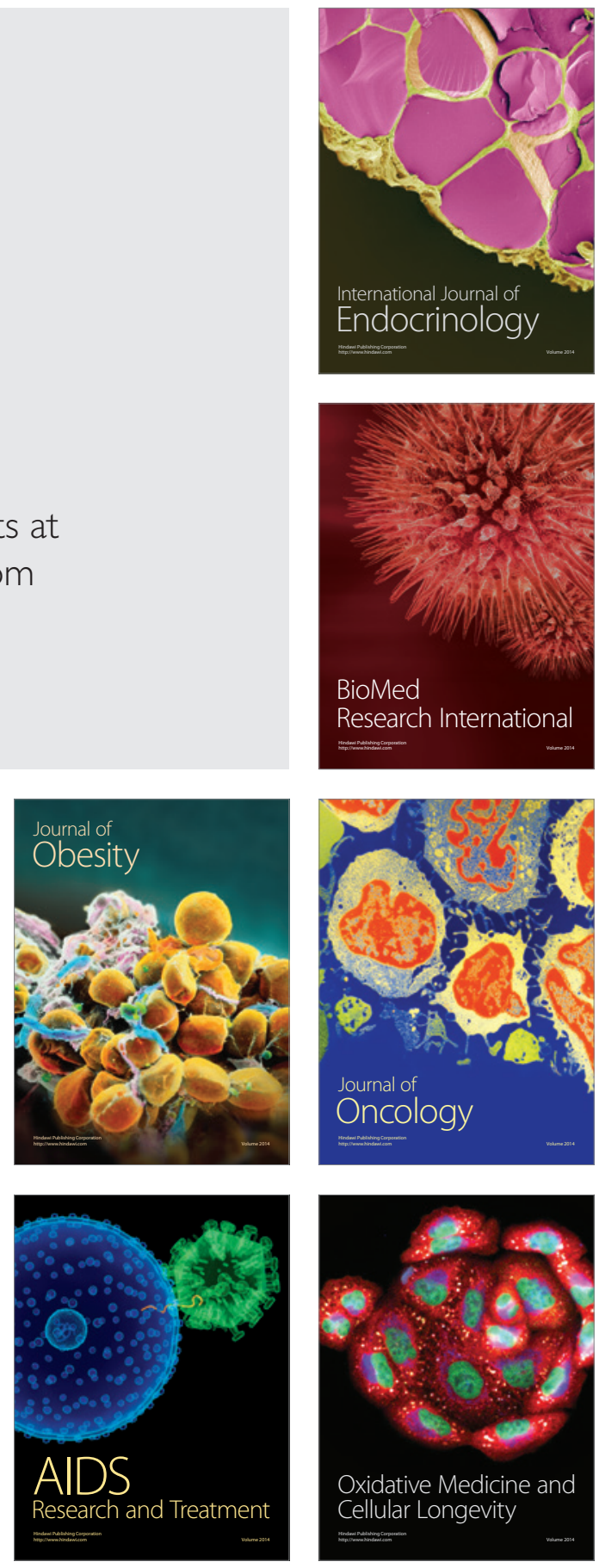